\title{
COMPREENSÕES SOBRE NATUREZA DA CIÊNCIA DE UMA LICENCIANDA EM QUÍMICA A PARTIR DE SUAS REFLEXÕES SOBRE UM ESTUDO DE CASO HISTÓRICO
}

\author{
GABRIELLA LEONE FERNANDES VELOSO * \\ https://orcid.org/0000-0001-9418-9673 \\ PAULA CRISTINA CARDOSO MENDONCุA * * \\ https://orcid.org/0000-0003-1762-4840 \\ NILMARA BRAGA MOZZER *** \\ https://orcid.org/0000-0002-2060-7964
}

RESUMO: Nesta pesquisa, analisamos as compreensões sobre Natureza da Ciência de uma licencianda em química a partir de suas reflexões sobre um estudo de caso histórico expressas em seu portfólio. O estudo de caso trata da história da síntese da amônia em escala industrial e sua abordagem se deu no contexto de um curso de formação inicial de professores sobre Natureza da Ciência. A análise textual discursiva foi a metodologia empregada na análise dos textos do portfólio. Os resultados desta pesquisa evidenciam uma compreensão contextualizada de diferentes aspectos de Natureza da Ciência pela licencianda. Isso sugere potencialidades de conjugar estudos de caso histórico e portfólios na formação inicial de professores de ciências para propiciar momentos de reflexões sobre Natureza da Ciência.

Palavras-chave: Natureza da Ciência. Caso Histórico. Portfólio.

\section{ENTENDIMIENTOS ACERCA DE LA NATURALEZA DE LA CIENCIA DE UNA ESTUDIANTE DE GRADO EN QUIIMICA A PARTIR DE SUS REFLEXIONES SOBRE UN ESTUDIO DE CASO HISTÓRICO}

RESUMEN: En esta investigación, analizamos los entendimientos acerca de la Naturaleza de la Ciencia de una estudiante de grado en química a partir de sus reflexiones sobre un estudio de caso histórico presentadas en su portafolio. El estudio de caso se refiere a la historia de la síntesis del amoníaco a escala industrial y su enfoque ocurrió en el contexto de un curso de formación inicial de profesores sobre la Naturaleza de la Ciencia. Se utilizó como metodología para el análisis de los textos del

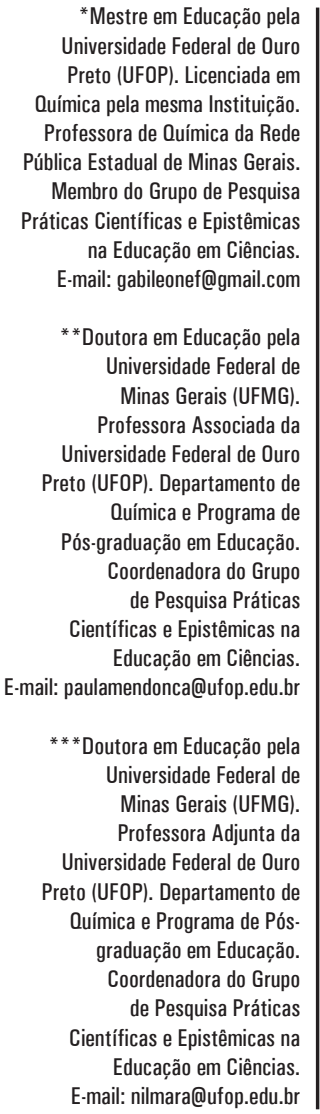

Universidade Federal de Ouro Preto (UFOP). Licenciada em imica pela mesma Instituicão. Pstadual de Minas Gerais. Membro do Grupo de Pesquisa Científicas e Epistêmicas cação em Ciencias.

Doutora em Educação pela Universidade Federal de Minas Gerais (UFMG)

Professora Associada da rersidade Federal de Ouro Química e Programa de graduação em Educação oordenadora do Grupo de Pesquisa Práticas Educacas em Ciencias. Educação em Ciências.

Doutora em Educação pela Universidade Federal de Minas Gerais (UFMG) Professora Adjunta da Pederal de Ouro eto (UFOP). Departamento de ímica e Programa de Pósgraduação em Educação. oordenadora do Grupo Pesquisa Práticas Educacão em Ciências.

' Universidade Federal de Ouro Preto, Departamento de Química e Programa de Pós-graduação em Educação., Ouro Preto, MG · Brasil. 
portafolio el análisis textual discursivo. Los resultados de esta investigación evidencian una comprensión contextualizada de diferentes aspectos de la Naturaleza de la Ciencia por la estudiante. Eso sugiere potencialidades de conjugar estudios de caso histórico y portafolios en la formación inicial de profesores de ciencias para propiciar momentos de reflexiones acerca de la Naturaleza de la Ciencia.

Palabras clave: Naturaleza de la Ciencia. Caso Histórico. Portafolio.

\section{UNDERSTANDINGS ON THE NATURE OF THE SCIENCE OF PRE- SERVICE CHEMISTRY TEACHER FROM HER REFLECTIONS ON A HISTORICAL CASE STUDY}

ABSTRACT: In this research, we analyzed the understandings about Nature of Science of pre-service chemistry teacher from her reflections on a historical case study expressed in her portfolio. The case study deals with the history of ammonia synthesis on an industrial scale and its approach took place in the context of an initial teacher training course on Nature of Science. Discursive textual analysis was the methodology used to analyze the texts in the portfolio. The results of this research show a contextualized understanding of different aspects of Nature of Science by the pre-service teacher. This suggests the potential to combine historical case studies and portfolios in the initial training of science teachers to provide moments of reflection on Nature of Science.

Keywords: Nature of Science. Historical Case. Portfolio. 


\section{INTRODUÇÃO}

Nas últimas décadas, o interesse em promover e investigar a compreensão sobre ciência dos professores (tema reconhecido na literatura pelo termo Natureza da Ciência, $\mathrm{NdC}$ ) tem sido amplamente explorado em diferentes países e em diversos níveis educacionais (ACEVEDO-DÍAZ; GARCÍA-CARMONA, 2016; ALLCHIN, 2011; AZEVEDO; SCARPA, 2017a; BARTHOLOMEW; OSBORNE; RATCLIFFE, 2004; IREZ, 2006; LEDERMAN, 2007; LEDERMAN; ABD-EL-KHALICK; BELL; SCHWARTZ, 2002; LEDERMAN; WADE; BELL, 1998). Esse interesse se faz importante ao observar que ainda existem poucas discussões sobre $\mathrm{NdC}$ em cursos de formação de professores (ACEVEDO-DÍAZ; GARCÍA-CARMONA, 2016). Nesse sentido, alguns autores (por exemplo, ALLCHIN, 2011) sugerem que a instrução sobre $\mathrm{NdC}$ dos professores em formação seja estruturada a partir de contextos que possibilitem a realização de uma análise crítica, problematizadora e reflexiva da prática científica; por exemplo, a partir da análise de estudos de caso histórico.

Estudos de caso histórico são apontados como uma possibilidade de abordagem eficaz na promoção da compreensão de $\mathrm{NdC}$ na formação de professores da área de ciências (PORTO, 2019). Esses abordam episódios da história da ciência que já foram palco de controvérsias no passado e cujas soluções já se encontram claramente delimitadas ou são consensuais na comunidade científica. Em geral, eles apresentam uma análise densa e profunda de um recorte histórico delimitado, narram os acontecimentos em detalhes com a preocupação de não glorificar alguns cientistas e não mitificar a ciência (ALLCHIN; ANDERSEN; NIELSEN, 2014; PORTO, 2019).

Neste sentido, a abordagem de estudos de caso histórico é oposta a uma análise enciclopédica (baseada em datas e acontecimentos, que relatam e situam os "precursores" das ideias científicas atuais desde a antiguidade mais remota), factual (baseada em curtas biografias dos autores, com enunciação das leis e das teorias atualmente aceitas, sem dar detalhes aos caminhos para obtê-las) e internalista (fechada em torno das ideias da própria ciência) da história da ciência (PORTO, 2019).

Por suas características, o uso de casos históricos no ensino de ciências pode contribuir para o entendimento de como a ciência se desenvolve, isto é, quais os processos que levam as afirmativas científicas a serem propostas, comunicadas, avaliadas e legitimadas no seio das comunidades científicas; como os problemas em investigação são resolvidos nestas comunidades científicas e quais as normas e os critérios utilizados para a resolução das controvérsias; e para a análise crítica da confiabilidade das afirmativas científicas (ALLCHIN et al., 2014).

O uso de casos históricos apresenta-se como uma importante estratégia para um ensino sobre ciência situado e contextualizado, uma vez que caminha na direção contrária de um ensino normativo de $\mathrm{NdC}$ baseado em crenças ou visões apriorísticas sobre o que conta como ciência e conhecimento (HODSON, 2014, MOURA; CAMEL; GUERRA, 2020).

Além de pensarmos sobre como inserir $\mathrm{NdC}$ no currículo dos cursos de formação de professores de ciências, torna-se relevante discutirmos como avaliar tais conhecimentos. Nesse sentido, um número significativo de instrumentos de pesquisa tem sido gerado visando avaliar os conhecimentos sobre $\mathrm{NdC}$ de professores (GUERRA-RAMOS, 2012). Entre esses instrumentos podemos citar 
os questionários elaborados por Kimball (1968), denominado Nature of Science Scale (NOSS); e Views of Nature of Science Questionnaire (VNOS), elaborado por Lederman et al. (2002). No entanto, alguns problemas são apontados na literatura quanto a essas formas de avaliação.

De acordo com Guerra-Ramos (2012), algumas pesquisas tendem a comparar as respostas dos professores às perspectivas desenvolvidas em filosofia, história ou sociologia da ciência, a partir do uso de instrumentos metodológicos baseados em testes e escalas que mensuram as visões de $\mathrm{NdC}$. Desta forma, os conhecimentos sobre ciência dos professores são determinados a priori.

Isso é justificado em função da necessidade de se ter critérios normativos de avaliação. Porém, não existe uma única perspectiva de $\mathrm{NdC}$ que seja adequada em diferentes situações, sendo necessário desenvolver uma que seja menos rígida, filosoficamente apoiada e defensável. Por exemplo, é problemático generalizar que o conhecimento é provisório para todos os contextos. Por outro lado, instrumentos de avaliação podem dizer que se trata de uma visão ingênua dos professores afirmarem o contrário (ELBY; HAMMER, 2001).

Segundo Guerra-Ramos (2012), muitos dos instrumentos de avaliação possuem questões descontextualizadas e que não exploram as ideias sobre ciência dos professores em contextos pedagogicamente relevantes. Estes auxiliam a realização de reflexões do professor sobre o tema e assim permitem investigar sua compreensão sobre ciência de modo mais adequado. Por exemplo, a investigação da compreensão sobre ciência dos professores, a partir das ações tomadas por eles em situações que envolvem sua prática docente - como os exemplos que eles fornecem em sala de aula - pode deixar claro a compreensão dos mesmos sobre provisoriedade e certeza do conhecimento científico. Nessa perspectiva, a literatura (por exemplo, ALLCHIN, 2011; ELBY; HAMMER, 2001; GUERRA-RAMOS, 2012) tem indicado a necessidade de se pensar em formas alternativas de avaliar o conhecimento sobre $\mathrm{NdC}$ de professores.

Pensando na avaliação dos conhecimentos sobre $\mathrm{NdC}$ de professores em formação, quando estes participam de processos de aprendizagem sobre o tema, o portfólio pode ser um instrumento alternativo que possui potencial para ser utilizado com o objetivo de avaliar de forma contextualizada. O portfólio pode ser entendido como "um instrumento de estimulação do pensamento reflexivo, facilitando oportunidades para documentar, registrar e estruturar os procedimentos e a própria aprendizagem" (SÁ-CHAVES, 2000, apud VIEIRA, 2002, p. 150). O sujeito do processo formativo deve explicitar e refletir sobre o próprio processo de aprendizagem, destacando os momentos cruciais os quais ele superou ou identificou um problema, ao elaborar o portfólio (HERNÁNDEZ, 1998).

De acordo com Collins (1992), o portfólio incentiva a integração de conhecimentos e habilidades aprendidas de diferentes formas, promovendo não somente a avaliação do conhecimento do sujeito no processo formativo, mas também a autoavaliação. Na mesma perspectiva, Hernández (1998) aponta que o portfólio é caracterizado como um instrumento de avaliação da aprendizagem, devido ao processo constante de reflexão realizado pelo sujeito, bem como da relação entre as finalidades educativas e as atividades realizadas para a sua elaboração.

Diante desses apontamentos, assumimos a hipótese de que o portfólio possibilita reflexões sobre $\mathrm{NdC}$ de professores de ciências em formação, quando esses participam 
de processos de aprendizagem sobre o tema. Por meio dessas reflexões, acreditamos ser possível avaliar de maneira profunda e contextualizada os seus conhecimentos sobre $\mathrm{NdC}$, porque o portfólio é elaborado ao longo de todo o processo de aprendizagem, o que permite que o professor em formação articule suas ideias sobre o tema.

Levando em consideração os apontamentos destacados, o presente trabalho tem como objetivo analisar as compreensões de uma licencianda em química sobre Natureza da Ciência a partir das reflexões sobre um estudo de caso histórico expressas em seu portfólio. Como uma implicação deste estudo, pretende-se evidenciar as potencialidades da associação entre estudos de caso históricos e portfólios na promoção de momentos de reflexão sobre $\mathrm{NdC}$ durante a formação inicial de professores de ciências.

\section{NATUREZA DA CIÊNCIA E CASOS HISTÓRICOS}

No campo da Educação em Ciências, o termo Natureza da Ciência tem sido utilizado para fazer menção aos conhecimentos epistemológicos da ciência que são potencialmente úteis aos estudantes da educação básica e professores desta área, e que caracterizam adequadamente as disciplinas da área de ciências da natureza. Esse construto híbrido apropria-se de reflexões das disciplinas metacientíficas, preponderantemente: filosofia, história e sociologia da ciência (IZQUIERDO-AYMERICH; ADÚRIZ-BRAVO, 2003); mas também psicologia e economia da ciência (SANTOS; MAIA; JUSTI, 2020)

Alguns pesquisadores, como Acevedo-Díaz, Vázquez-Alonso, Manassero-Mas e Acevedo-Romero (2007), apontam que, devido a sua natureza interdisciplinar, o entendimento sobre $\mathrm{NdC}$ é pouco consensual, mas que existem certos acordos para fins pedagógicos. Lederman (1992) e Lederman et al. (2002) apoiam esta visão, destacando alguns aspectos caraterísticos da ciência que consideram consensuais, como: conhecimento cientifico tem bases empíricas (baseia-se em experimentos e observações); é confiável, porém suscetivel a falhas e/ ou provisório (sujeito a mudanças, não sendo uma verdade absoluta); é produto da imaginação $e$ criatividade humana; é guiado por teorias e subjetivo (influenciado pelos conhecimentos prévios, crenças, experiências e expectativas dos cientistas); é culturalmente e socialmente imbricado (é influenciado pelos contextos sociais e culturais). Além disso, os autores destacam que observações são diferentes de inferências; teorias e leis são categorias distintas do conhecimento; não existe um único método científico que seja capaz de produzir conhecimento confiável.

Esses aspectos fazem parte da lista consensual ${ }^{1}$ para ensino e avaliação de NdC elaborada por Lederman e colaboradores (2002). Para justificar a escolha dos aspectos da lista, os autores utilizaram três critérios: aspectos que são compreensíveis aos estudantes da educação básica, consenso entre especialistas (ou boa parte deles) e a utilidade desses aspectos para os cidadãos. Os autores também consideram que a lista seja relevante para fins pedagógicos, uma vez que, sob seus pontos de vista, os estudantes não precisam se preocupar com as divergências que acontecem entre os especialistas (por exemplo, a diferença entre realismo e construtivismo).

Em contrapartida, pesquisadores como Irzik e Nola (2011), Matthews (1998), Hodson (2014), Allchin (2011), Mendonça (2020) defendem que não há uma única 
forma de caracterizar a ciência e que ela não pode ser plenamente descrita, levando em consideração a heterogeneidade e a especificidade das áreas da ciência, mesmo que seja para fins educativos. Nessa perspectiva, a lista consensual não contempla aspectos importantes sobre a ciência, porque, ao simplificar a ciência a partir de uma lista de tópicos fundamentais, pode-se fazer generalizações que não são aplicáveis a todos os campos (MOURA et al., 2020; IRZIK; NOLA, 2014; WONG; HODSON, 2010).

Por exemplo, enquanto as geociências são fundamentalmente interpretativas e históricas, e objetivam explicar muitos eventos do passado a partir da proposição de modelos causais, outras áreas do conhecimento como a química, mais especificamente, a química orgânica, têm caráter mais experimental. Esta atende a objetivos como a síntese de novas moléculas e substâncias e a análise de várias de suas propriedades a partir de métodos físicos e químicos. Por outro lado, mesmo dentro de uma mesma área do conhecimento, os modos e objetivos de uma investigação podem ter caracteres distintos. Como é o caso da química teórica, que se utiliza de técnicas computacionais e de modelos matemáticos na tentativa de prever novas moléculas e seus comportamentos (MENDONÇA, 2020).

De acordo com Allchin (2011), a lista consensualé descontextualizada e também não contempla aspectos importantes como: critérios para analisar a credibilidade das afirmações científicas, o papel do financiamento na pesquisa científica, a motivação do cientista em fazer ciência, o processo de revisão do conhecimento entre os pares, as bases cognitivas da ciência, as fraudes e a validação de novos métodos científicos etc.

Santos et al. (2020) endossam as críticas à lista consensual, devido à natureza complexa e multifacetada da ciência. Isso torna problemático caracterizá-la de forma homogênea, desconsiderando o contexto no qual as características são enunciadas, pois é pelo contexto que os aspectos adquirem significado. Sob essa perspectiva, pesquisadores defendem o ensino contextualizado de NdC (ALLCHIN, 2011; ALLCHIN et al., 2014; JUSTI; MENDONÇA, 2016; MOURA et al., 2020), isto é, a discussão de aspectos característicos de $\mathrm{NdC}$ a partir da análise de estudos de caso.

De acordo com Porto (2019), os estudos de caso podem ser compreendidos como a análise, com certa profundidade, de algum episódio delimitado da história da ciência. Eles diferem do emprego da história da ciência apenas para "ilustrar" algum conteúdo a ser estudado, com a citação de datas de acontecimentos ou nomes de cientistas envolvidos em alguma descoberta, como frequentemente ainda se observa em materiais didáticos. Essas "ilustrações" não contextualizam de fato e não contribuem para a compreensão do conteúdo ensinado, além de não favorecer a compreensão do processo de construção da ciência (PORTO, 2019).

Para que os sujeitos possam compreender $\mathrm{NdC}$ a partir dos estudos de caso, eles devem estar envolvidos no contexto histórico, e não apenas observar ou comentar sobre os fatos históricos. Uma forma de imergir os professores em formação no contexto histórico seria envolvê-los em dramatizações históricas, júris simulados, experimentos históricos, entre outros recursos, que favoreçam uma participação ativa dos mesmos (JUSTI; MENDONÇA, 2016).

Para se discutir sobre $\mathrm{NdC}$ a partir dos estudos de caso, Allchin et al. (2014) ressaltam também que os sujeitos, ao lidar com casos já consensuais, devem ter a perspectiva de uma ciência em construção, de modo a tomar conhecimento das incertezas com as quais os cientistas do passado tiveram que lidar. Neste 
sentido, as instruções envolvendo contextos históricos devem ser adequadamente planejadas para o envolvimento efetivo dos sujeitos, visando levá-los a entender o contexto de desenvolvimento das ideias científicas à luz do período histórico (JUSTI; MENDONÇA, 2016).

De acordo com Allchin et al. (2014), a partir dos casos históricos pode-se discutir diferentes aspectos da ciência, tais como: (i) o papel do debate e da crítica na ciência; (ii) as parcialidades teóricas, culturais e cognitivas; (iii) as motivações, as chances e a colaboração entre cientistas; (iv) conexões interdisciplinares entre as áreas da ciência; (v) experiência, credibilidade e conflitos de interesse entre cientista, entre outros. Todos esses aspectos podem contribuir para o entendimento de como a ciência funciona, para a análise crítica da confiabilidade das afirmativas científicas e, portanto, para o desenvolvimento de uma visão mais ampla sobre ciência (ALLCHIN, 2011).

Alguns autores (por exemplo, ALLCHIN, 2013; IRZIK; NOLA, 2011; LEDERMAN et al., 2002; MAT'THEWS, 1998; MCCOMAS, 2008; NIELSEN, 2012) enfatizam que para promover a compreensão sobre $\mathrm{NdC}$ por parte de professores e estudantes, deve-se utilizar uma abordagem explícita, ou seja, a discussão dos aspectos de $\mathrm{NdC}$ deve ser promovida de forma clara. Isso não significa a enunciação desses aspectos, mas a sua abordagem a partir da realização e discussão de atividades bem planejadas.

Algumas pesquisas evidenciam que a aprendizagem de $\mathrm{NdC}$ não acontece satisfatoriamente de maneira implícita (ALLCHIN, 2011; MATTHEWS, 1998, MOURA et al., 2020). Isso se deve ao fato de que o modo implícito não possibilita a completa reflexão dos aspectos de $\mathrm{NdC}$ que podem emergir na condução de uma atividade de investigação científica ou de uma análise de caso, uma vez que, nesse tipo de abordagem, os sujeitos deveriam compreender tais aspectos somente a partir de suas experiências com as atividades.

Defendemos neste trabalho a utilização de uma abordagem explícita de $\mathrm{NdC}$ na formação de professores, visto a maior efetividade dessa abordagem em oposição à implícita (ACEVEDO-DÍAZ, 2009); e a utilização dos estudos de caso histórico para promover uma visão mais ampla sobre ciência dos professores em formação (ALLCHIN, 2011), porque poderão compreender sobre ciência a partir de uma imersão nela própria. Consideramos também que a compressão sobre ciência dos professores em formação não pode ser limitada a uma lista de características da ciência, como a lista consensual de Lederman et al. (2002), tendo em vista a natureza complexa e de múltiplas faces do empreendimento científico (IRZIK; NOLA, 2011; SANTOS et al., 2020).

Desta forma, nos guiamos por autores que, como Santos et al. (2020), veem a ciência de uma forma bem ampla a partir de várias disciplinas metacientíficas e consideram o contexto no qual as ideias de $\mathrm{NdC}$ são enunciadas pelos sujeitos. Assumimos também a reflexão como elemento central para guiar a compreensão dos futuros professores sobre $\mathrm{NdC}$, uma vez que esta possibilita o desenvolvimento dos conhecimentos profissionais de professores de ciências em formação, dentre os quais se encontram aqueles referentes à NdC (OLIVEIRA; MOZZER; ANDRADE, 2017).

Diversas pesquisas têm sido desenvolvidas com o intuito de investigar a compreensão dos professores sobre ciência (BARTHOLOMEW et al., 2004; IREZ, 2006; LEDERMAN, 2007; LEDERMAN et al., 2002; LEDERMAN et al., 1998). No trabalho realizado por Guerra-Ramos (2012) é apresentada uma análise crítica 
de algumas dessas pesquisas que buscaram avaliar a compreensão sobre ciência dos professores. Evidencia-se que um número considerável de instrumentos tem sido gerado com esse objetivo, destacando-se entre eles, questionários com questões abertas, fechadas ou mistas e entrevistas estruturadas ou abertas, com perspectivas de análise quantitativas e/ou qualitativas. Por exemplo, o questionário NOSS proposto por Kimball (1968), foi um dos primeiros instrumentos de avaliação elaborado para avaliar os conhecimentos dos professores de ciências (GUERRA-RAMOS, 2012). Baseado em declarações que expressam uma perspectiva particular sobre $\mathrm{NdC}$ apoiado por visões de filósofos da ciência, NOSS foi amplamente utilizado e influenciou a elaboração de outros instrumentos com essa mesma abordagem filosófica normativa.

Outro exemplo, é o questionário VNOS, elaborado porLederman et al. (2002), amplamente divulgado e utilizado por pesquisadores para avaliar os conhecimentos de professores e alunos da área de ciências. O instrumento apresenta questões abertas, as quais objetivam avaliar a compreensão dos aspectos de $\mathrm{NdC}$ presentes na lista consensual. Por exemplo, a questão: "Uma teoria cientifica desenvolvida por um cientista (como a teoria atômica ou a teoria da evolução) pode modificar-se?” (Tradução nossa), tem como objetivo avaliar se o sujeito compreende que o conhecimento científico é provisório. Ao responder a questão o sujeito também é solicitado a explicá-la e exemplificá-la.

Guerra-Ramos (2012) aponta alguns problemas quanto a essas formas de avaliação. Segundo a autora, por meio delas, espera-se muitas vezes que os professores explicitem e articulem seus conhecimentos sobre ciência a partir de perguntas diretas, como: “o que é ciência na sua visão?” ou "o que é um experimento?”, sem considerar as possíveis dificuldades que eles possam ter para expressar suas ideias. De acordo com alguns pesquisadores (por exemplo, ALLCHIN, 2011; AZEVEDO; SCARPA, 2017b; IRZIK; NOLA, 2011), muitas vezes essas perguntas são descontextualizadas e dificultam a realização de reflexão por parte do professor. Por exemplo, no VNOS é difícil recordar quais são os significados dos termos "lei" e "teoria" para responder a questão: "há diferença entre uma teoria científica e uma lei científica? Ilustre sua resposta com um exemplo", sem que seja fornecido um contexto, o qual auxilie a reflexão por parte do professor. Além disso, segundo Guerra-Ramos (2012), os professores podem nunca ter se deparado com tais questões ou refletido sobre as mesmas e sentirem dificuldades de articular as ideias, justificá-las e elaborá-las.

De acordo com a autora é necessário pensar em formas de avaliar a compreensão sobre ciência dos professores a partir de contextos pedagogicamente relevantes. Por exemplo, Nott e Wellington (1995, 1996 apud GUERRA-RAMOS, 2012) defendem uma metodologia baseada no que denominaram de "incidentes críticos" para investigar a compreensão sobre ciência de professores. Um incidente crítico pode ser entendido como um evento que descreve qualitativamente uma experiência em sala de aula, que permitirá que o professor apresente uma tomada de decisão que envolva algum tipo de explicação de natureza científica. Por exemplo, perante a resultados inesperados de um experimento realizado em sala de aula, o professor deve levantar questões sobre o conhecimento científico ou sobre a conduta de cientistas, de modo a explicar o que ocorreu. Nesse sentido, os incidentes críticos têm por objetivo fornecer uma visão das ideias sobre $\mathrm{NdC}$ do professor, a partir de suas ações que derivam de um contexto que pode ser vivenciado em sala de aula (GUERRA-RAMOS, 2012). 
De acordo com a autora, os problemas inerentes aos instrumentos de pesquisa - os quais os professores devem responder no próprio local, com tempo determinado e através da escrita (em oposição à complementação de ideias via entrevista) - estão relacionados ao fato deles não explorarem as ideias dos professores com maior profundidade. Nesse sentido, a complexa rede de ideias sobre ciência pode perder seu significado quando avaliadas através de instrumentos como testes e escalas, nos quais os resultados são dependentes dos critérios de "adequação" adotados pelos pesquisadores. Por esse motivo, eles fornecem uma visão restrita da compreensão sobre ciência do professor, ou seja, apenas uma noção de como eles são influenciados ou foram expostos a concepções acadêmicas sobre NdC. Como exemplo, podemos citar o questionário NOSS (KIMBALL, 1968), que possui 29 declarações descontextualizadas, as quais os professores são solicitados a "concordar", "discordar" ou escolher uma resposta neutra.

A revisão realizada por Guerra-Ramos (2012) e a consulta a outras pesquisas na área (por exemplo, ALLCHIN, 2011; ELBY; HAMMER, 2001), indicam que é importante pensar em formas alternativas de investigar o conhecimento sobre $\mathrm{NdC}$ dos professores, destacando a importância de se analisar as ideias apresentadas pelos sujeitos a partir de um contexto. De acordo com esses apontamentos e com as características destacadas na literatura sobre o portfólio, julgamos que esse instrumento tem potencial para ser utilizado na investigação dos conhecimentos sobre $\mathrm{NdC}$ de professores em formação a partir de suas reflexões sobre o tema quando eles participam de processos de ensino e aprendizagem sobre NdC.

É necessário ressaltar que este trabalho não pretendeu fazer comparações entre os instrumentos de avaliação dos conhecimentos sobre $\mathrm{NdC}$ já conhecidos na literatura da área e o portfólio. Isso porque os primeiros apresentam objetivos diversos, os quais são diferentes dos objetivos do portfólio. Um questionário como o VNOS, por exemplo, visa avaliar a compreensão dos aspectos de $\mathrm{NdC}$ presentes na lista consensual. A discussão aqui apresentada visa ressaltar a necessidade de se pensar em novas formas de investigar a compreensão sobre $\mathrm{NdC}$ de professores e, ao sugerir o portfólio para essa investigação, propor um instrumento alternativo que possa ser utilizado em casos em que a investigação é realizada em processos de aprendizagem e reflexão sobre o tema, como na análise de estudos de caso.

\section{PORTFÓLIO: UM INSTRUMENTO DE REFLEXÃO}

De acordo com Hernández (1998), o portfólio pode ser compreendido como um conjunto de diferentes classes de documentos, como notas pessoais, experiências de aula, trabalhos pontuais, representações visuais, os quais fornecem evidências do conhecimento construído pelo sujeito ao longo de um período e indícios das estratégias e disposições utilizadas por ele para aprender e continuar aprendendo. $\mathrm{O}$ portfólio não deve ser entendido como uma pasta acumulativa de trabalhos, mas um instrumento que visa mostrar o progresso e avanço do sujeito em processo formativo, permitindo que ele desenvolva a tomada de decisão ao produzir um trabalho criativo, aprendendo a selecionar evidências do seu aprendizado e a fazer julgamentos sobre o seu desempenho (PAULSON; PAULSON; MEYER, 1991). 
Para a elaboração de um portfólio é desejável que o sujeito não apenas selecione e organize as evidências de aprendizagem, mas também realize reflexões sobre sua própria aprendizagem (ZANELLATO, 2008). O portfólio deve conter, por exemplo, reflexões sobre os temas abordados e sínteses das discussões realizadas em sala de aula, que servirão para a avaliação da aprendizagem do sujeito em processo formativo (ALVARENGA; ARAUJO, 2006).

De acordo com Kish, Sheehan, Cole, Struyk e Kinder (1997), o portfólio desenvolve o pensamento reflexivo e auxilia o sujeito a questionar-se, analisar problemas e discutir assuntos. Nesse sentido, sendo o portfólio um instrumento que objetiva a reflexão, ele pode permitir que o sujeito veja a realidade com maior clareza e pense criticamente sobre ela, desenvolvendo, assim, seu pensamento crítico (ALVARENGA; ARAUJO, 2006).

No contínuo processo de reflexão, o professor em formação poderá demonstrar sua capacidade de autoavaliação, que pode ocorrer nos momentos em que analisa e interpreta sua aprendizagem. De acordo com Zanellato (2008), a reflexão possui uma relação natural com a autoavaliação, que permite que o sujeito avalie seu desempenho.

A reflexão que o sujeito realiza expressa a sua compreensão sobre as experiências vividas e possibilita-o voltar a sua atenção para as consequências de suas ações. A reflexão auxilia a identificar motivos e consequências de determinados fatos e a análise e questionamento de seu próprio desempenho. Dessa forma, o portfólio se torna um material de registro das dinâmicas do crescimento da aprendizagem pessoal, porque permite comparar os diferentes momentos vivenciados. A elaboração desse instrumento de reflexão promove o autoconhecimento e possibilita a autorreflexão (ZANELLATO, 2008).

O portfólio pode ser utilizado também na formação inicial de professores como uma metodologia que tem por objetivo implementar e favorecer os processos de reflexão sobre a prática pedagógica, possibilitando um registro contínuo do progresso, das aprendizagens e das experiências do professor em formação, resultantes das atividades exercidas durante um período (RODRIGUES, 2009).

Segundo Silva e Araújo (2005), baseadas em Paulo Freire, reflexão é o movimento realizado entre o fazer e o pensar, e entre o pensar e o fazer. Nesse sentido, a reflexão permite que o sujeito reveja os acontecimentos e isto lhe possibilita monitorar, compreender e refletir sobre o seu conhecimento, de modo que possa vir a ter consciência do seu estado de conhecimento, o que caracteriza também a metacognição (VILLAS BOAS, 2005).

De acordo com Ribeiro (2003), a metacognição está relacionada ao conhecimento sobre o conhecimento, à tomada de consciência dos processos e das competências para a realização de tarefas, bem como ao controle (ou autorregulação), que está relacionado com a nossa capacidade de avaliar a execução da tarefa e de fazer correções quando necessário.

Segundo Villas Boas (2005), o portfólio, como instrumento de avalição, tem sido utilizado com grande potencial para associar currículo e práticas pedagógicas, visando o desenvolvimento metacognitivo dos sujeitos. Nesse sentido, o portfólio fornece a oportunidade para avaliações que favorecem uma visão mais abrangente do desempenho do sujeito em processo formativo, pois além de revelar muito 
sobre o sujeito que o elabora, permite compreender o processo educativo de forma individual (PAULSON et al., 1991).

É importante ressaltar a necessidade da orientação quanto à elaboração do portfólio, pois a não compreensão dos seus objetivos, pode comprometer a eficiência desse instrumento de aprendizagem. Para evitar essa incompreensão é fundamental que exista o diálogo entre o professor formador e o professor em formação em vários momentos ao longo do período de um curso ou disciplina, de forma a ampliar e diversificar o olhar do professor em formação e mediar a elaboração do portfólio (ZANELLATO, 2008). Esclarecer os critérios para a reflexão é primordial para o desenvolvimento do portfólio pelo sujeito, mas é necessário ter cautela para não correr o risco de instrumentalizar suas reflexões, e assim, dificultar processos produtivos de reflexão sobre os seus próprios critérios; o que parece ser relevante de uma perspectiva metacognitiva (QVORTRUP; KEIDING, 2015).

Nesta pesquisa utilizamos o portfólio como instrumento, considerando-se a sua relevância para a aprendizagem e a sua possível contribuição ao ensino e à pesquisa da área como uma proposta alternativa para avaliar as compreensões de $\mathrm{NdC}$ de professores, no contexto de análise de estudos de caso.

\section{METODOLOGIA DA PESQUISA}

\section{Contexto da coleta de dados}

$\mathrm{O}$ curso de formação inicial sobre a temática $\mathrm{NdC}$ foi desenvolvido no âmbito do Programa Institucional de Bolsa de Iniciação à Docência (Pibid), no subprojeto de química, de uma Universidade Federal localizada na região sudeste do Brasil. Na época, participavam do Pibid 16 licenciandos em química, de um curso noturno com duração de 8 semestres. Os licenciandos possuíam conhecimentos diversificados sobre química e ensino de química, pois se encontravam em diferentes períodos do curso quando as atividades relatadas neste trabalho foram desenvolvidas.

Durante a realização do curso de formação, os licenciandos tinham uma rotina de atividades semanais, dentre as quais se incluíam aquelas relacionadas à vivência do cotidiano escolar, encontro dos grupos de trabalho, leituras, realização das atividades propostas no curso de formação e um encontro presencial semanal com todos os participantes do Pibid.

O curso ocorreu em três etapas ao longo de três semestres letivos consecutivos. A primeira etapa visava favorecer o desenvolvimento dos conhecimentos teóricos sobre $\mathrm{NdC}$ dos licenciandos. Nessa etapa, foram realizadas leituras e discussões de textos sobre os objetivos do ensino de ciências e da formação de professores; e a inserção da história da química no ensino de química. Além das leituras, durante essa primeira etapa do curso foram explorados três estudos de caso da ciência (dois casos históricos e um caso contemporâneo). ${ }^{2}$ A segunda e a terceira etapas visavam a proposição e o desenvolvimento de materiais para se trabalhar o tema $\mathrm{NdC}$ na Educação Básica.

Uma das tarefas principais da primeira etapa do curso de formação, foco desta pesquisa, foi a reflexão sobre $\mathrm{NdC}$ a partir de cada um dos estudos de 
caso. Os licenciandos se organizaram em grupos para realizar as apresentações dos estudos de caso para os pares, as quais foram seguidas de discussões sobre aspectos da construção da ciência salientes em cada um deles.

Neste trabalho, objetivamos analisar as compreensões sobre $\mathrm{NdC}$ de uma licencianda em química a partir de suas reflexões sobre um estudo de caso histórico realizado na primeira etapa do curso. O caso histórico envolveu uma controvérsia sobre um fato histórico, a qual relacionava-se à concessão do prêmio Nobel de química de 1918, atribuído a Fritz Haber pela síntese da amônia em larga escala, a partir de seus elementos constituintes (JUSTI; MENDONÇA, 2016). Para a apresentação do caso por meio do que foi denominado de "corte histórica", os licenciandos foram divididos em dois grupos de oito integrantes cada um, a favor da concessão do prêmio Nobel de química a Fritz Haber (grupo de defesa do "réu") e, o outro, contrário (grupo de acusação ao "réu").

Os licenciandos receberam um mesmo conjunto de textos diversos sobre o tema, que serviram como material suporte para a elaboração dos argumentos de defesa e ataque ao réu. Os textos abordavam a história de Fritz Haber, o desenvolvimento da produção de amônia e o cenário em que isto aconteceu. Alguns textos eram fontes primárias (como o discurso de Haber ao receber o prêmio Nobel), e outros, fontes secundárias (artigos sobre a síntese da amônia, alguns aspectos dessa história relacionados à Haber, e sobre o contexto histórico, político e econômico do século XIX e início do século XX).

Em suma, a partir do estudo de caso, os licenciandos poderiam ter a noção sobre como a ciência pode influenciar e ser influenciada pelos diferentes contextos (como social, político, econômico etc.). A história poderia auxiliar a visualizar a ciência em construção e esclarecer aspectos do trabalho e motivações do cientista, tais como a influência da personalidade do cientista no fazer ciência, o conhecimento científico ser produzido de maneira colaborativa, a necessidade de financiamento para a condução de pesquisas, entre outros.

\section{Coleta de dados}

Logo no início do curso, os participantes foram informados de que os registros realizados durante os encontros e as atividades desenvolvidas durante o projeto seriam utilizados em pesquisas. Eles assinaram Termos de Consentimento Livre e Esclarecido, autorizando o registro e a utilização dos dados produzidos. O projeto de pesquisa foi aprovado pelo comitê de ética em pesquisa de uma Universidade Federal do Sudeste do país.

$\mathrm{Na}$ primeira etapa do curso de formação, uma das atividades realizadas individualmente pelos licenciandos consistia em elaborar, semanalmente, textos que comporiam o seu portfólio. De acordo com as instruções dadas pela coordenadora do curso, nesses textos, os licenciandos deveriam realizar descrições e reflexões referentes às atividades semanais. Os textos eram enviados para o e-mail da coordenadora no prazo de uma semana após cada encontro presencial.

Periodicamente, os licenciandos recebiam um feedback sobre os textos produzidos, o qual tinha como objetivo auxiliá-los na elaboração desses textos. Esse feedback foi importante, pois, uma vez que eles nunca haviam elaborado um portfólio, 
muitos deles apenas narravam o encontro presencial ou as atividades realizadas durante a semana. Por outro lado, era esperado que os licenciandos refletissem sobre o tema principal do curso, a partir dos estudos de caso e das discussões sobre a temática realizadas nos encontros presenciais. Além disso, esperava-se que eles registrassem suas impressões sobre as atividades realizadas no curso.

Isso porque, na pesquisa desenvolvida, o portfólio é entendido como um conjunto de textos produzidos por professores em um curso de formação inicial, em que eles deveriam escrever e refletir sobre o que é ciência e sobre como ela se desenvolve ao vivenciarem uma abordagem de ensino contextualizada. Consideramos nesta pesquisa que o ato de reflexão sobre os pensamentos, os sentimentos e a própria aprendizagem pelos licenciandos poderia favorecer o desenvolvimento de habilidades metacognitivas ao auxiliá-los a se autoavaliarem e a pensar no que aprenderam ou não nas atividades do curso. Julgamos que esse processo de exame dos próprios pensamentos é importante para auxiliar professores que estão aprendendo temas complexos, como $\mathrm{NdC}$.

Ao final do curso de formação, a licencianda, que faz parte da amostra desta pesquisa, elaborou 27 textos para seu portfólio, sendo 14 deles elaborados na primeira etapa do curso. Destes, 4 textos, enumerados de 5 a 8 , se referem à preparação e apresentação do estudo de caso histórico no qual esta pesquisa está centrada.

\section{Amostra}

A amostra dessa pesquisa consiste de uma licencianda que, ao ingressar no curso de formação, cursava o $4^{\circ}$ período de uma licenciatura em química. Ela ainda não havia tido contato prévio formal com o tema $\mathrm{NdC}$.

A escolha da licencianda como amostra dessa pesquisa se justifica pelo fato de que, para analisar a compreensão sobre ciência dos licenciandos, consideramos necessário que dois critérios fossem atendidos: (i) que os licenciandos fossem frequentes no curso; (ii) que os licenciandos realizassem reflexões sobre ciência nos textos de seus portfólios, destacando os aspectos de $\mathrm{NdC}$ que puderam ser compreendidos a partir do estudo de caso. No caso específico da licencianda investigada, sua seleção como sujeito desta pesquisa se justifica pelo fato de a mesma ter fornecido esclarecimentos bem detalhados sobre os seus entendimentos a respeito dos aspectos de $\mathrm{NdC}$ expressos em suas reflexões, fato que possibilitounos uma análise mais acurada de suas compreensões. Isso não implica dizer que os demais portfólios não apresentavam potencial para análise, mas que o da licencianda selecionada foi escolhido de modo intencional pelas pesquisadoras, por apresentar mais elementos para discussão da questão de pesquisa aqui apresentada.

\section{Metodologia de análise de dados}

Por se tratar de um documento, o portfólio constitui uma fonte de dados estável, que pode ser consultado várias vezes, servindo de base para diferentes estudos, além de ser uma fonte de onde podem ser retiradas evidências que suportem as afirmações do pesquisador (LÜDKE; ANDRÉ, 2015). Levando-se em consideração essa definição, foi realizada uma análise documental a fim de 
identificar nos textos produzidos pela licencianda sua compreensão sobre ciência.

Optamos pela análise textual discursiva com intuito de sistematizar a análise do portfólio (MORAES, 2003; MORAES; GALIAZZI, 2006). A primeira fase da análise consistiu na desconstrução e unitarização dos textos, processo que resultou na definição das unidades de significado ou unidades de análise. A definição das unidades de significado (US) partiu da identificação dos aspectos de $\mathrm{NdC}$ emergentes das reflexões da licencianda, sejam eles expressos de forma explícita ou implícita. Cada texto analisado pode conter uma ou mais US, as quais foram enumeradas da seguinte forma: primeiramente, com o número do texto do qual fazia parte, seguida de um segundo número referente à ordem de identificação da US. Assim, o texto 6 dará origem às US $6.1 ; 6.2 ; 6.3$ etc. O texto 7 originará as US 7.1; 7.2; e assim por diante.

Levando-se em consideração a importância de analisar o contexto em que as ideias sobre ciência da licencianda emergiram, ao definir as US, buscamos também analisar se os aspectos de $\mathrm{NdC}$ eram exemplificados ou justificados. Consideramos uma exemplificação, os momentos nos quais a licencianda citou uma história que havia sido estudada para fazer menção à $\mathrm{NdC}$, porém, sem mais esclarecimentos sobre a relação do fragmento com a sua compreensão de $\mathrm{NdC}$. A US a seguir ilustra um momento de exemplificação, em que a licencianda mencionou a história de Fritz Haber para destacar que a ciência é um empreendimento humano:

"Refletindo sobre a história de Fritz. Haber, percebo que entre todas as histórias de cientistas já discutidas, talvez esta seja a que mais contribua para reforçar a visão humanizada sobre a ciência”. [US 7.2]

Consideramos uma justificação, os esclarecimentos da licencianda sobre o que ela pensou sobre ciência atrelado ao contexto histórico. A US a seguir ilustra um momento de justificação, em que a licencianda ressalta que a ciência não é linear.

"A história de Haber também nos faz atentar para o fato de que o conbecimento não éproduzido de forma linear, direta e livre de obstáculos. Muitas vezes os cientistas encontram diversas dificuldades durante seus estudos, como foi o caso de Haber. Alguns aspectos como o fato da sintese da amônia ser estudada por outros cientistas, mas sem grande êxito, além da aparente inviabilidade desta sintese contribuiram grandemente para que Haber às vezes se sentisse desmotivado e desanimado. Haber demorou alguns anos a chegar a algum resultado satisfatório, o que evidencia a presença de grandes complicações encontradas durante seus estudos”. [US 7.5]

O segundo passo da análise textual discursiva é a categorização. De acordo com Moraes (2003), as categorias podem ser produzidas a partir do método dedutivo (categorias criadas a priori) ou indutivo (categorias emergentes da análise), ou pela combinação do método dedutivo e indutivo, que seria um "processo de análise misto em que, partindo de categorias definidas a priori com base em teorias escolhidas previamente, o pesquisador encaminha transformações gradativas no conjunto inicial de categorias, a partir do exame das informações do corpus de análise" (MORAES, 2003). Neste trabalho, as categorias foram criadas de forma mista.

Para elencar as categorias, nos guiamos por autores que, como Santos et al. (2020), vislumbram $\mathrm{NdC}$ de forma ampla a partir da análise dos contextos que envolvem a ciência. Desse modo, não tínhamos como objetivo identificar se as compreensões 
sobre $\mathrm{NdC}$ da licencianda se enquadrava em uma visão sofisticada ou não da ciência pelo número de características de uma lista criada a priori, mas pelo grau de coerência dos aspectos ressaltados a partir da análise do estudo de caso realizada pela licencianda.

Buscamos estabelecer relações entre as US, reunindo aquelas que eram semelhantes entre si em termos de reflexão sobre o mesmo aspecto de $\mathrm{NdC}$, gerando assim, as categorias de análise, as quais foram posteriormente nomeadas. Por exemplo, a categoria denominada a ciência é contextualizada foi denominada dessa forma pelo fato da licencianda apresentar em vários momentos reflexões sobre as diferentes esferas que influenciam e são influenciadas pela ciência (social, política, econômica, religiosa etc.). Outro exemplo: a categoria denominada a ciência não é linear, se refere às reflexões da licencianda sobre as dificuldades encontradas pelos cientistas ao produzirem conhecimento.

Como um terceiro passo, teorizações foram construídas a partir das evidências encontradas na análise dos dados, que realçam diferentes aspectos que caracterizam a ciência de acordo com a literatura sobre o tema (por exemplo, ALLCHIN, 2011; ALLCHIN et al., 2014; JUSTI; MENDONÇA, 2016; LEDERMAN et al., 2002; SMITH; SCHARMANN, 1999). Dessa maneira, buscamos a elaboração de um metatexto sobre as compreensões da licencianda sobre ciência a partir da análise de suas reflexões sobre o estudo de caso histórico expressas em seu portfólio, que evidenciam como essas reflexões despertaram o seu olhar crítico para as características da ciência.

\section{ANÁLISE DOS DADOS}

A licencianda apresentou reflexões sobre ciência em todos os textos do portfólio referentes ao caso histórico, com exceção do texto 5, no qual realizou apenas uma descrição das atividades desenvolvidas durante a semana. Foram identificadas doze US e um total de cinco categorias. São elas: i) a ciência é contextualizada; ii) o conhecimento cientifico é produzido de forma colaborativa; iii) a ciência não é linear; iv) a ciência é um empreendimento humano; v) a ciência é amoral.

Todas as US definidas apresentavam um aspecto de $\mathrm{NdC}$, que foi ressaltado pela licencianda de maneira contextualizada, ou seja, a licencianda não apresentou aspectos de $\mathrm{NdC}$ de forma abstrata, pois eles não foram simplesmente declarados, mas emergiram da análise do estudo de caso, sendo eles exemplificados e/ou justificados. As US que exemplificam de forma mais clara os aspectos centrais das categorias expressas nas reflexões da licencianda foram exemplificadas e discutidas neste trabalho.

A categoria "a ciência é contextualizada" foi identificada nas US 6.1; 6.3; 7.1; 7.3; 8.3. Nessas US a licencianda refletiu sobre o contexto social vivenciado por Fritz Haber, de modo a justificar a necessidade da síntese da amônia em larga escala ou citando sua história como exemplificação desse aspecto de $\mathrm{NdC}$ (US 7.3). A US 8.3, apresentada a seguir, ilustra como esse aspecto de $\mathrm{NdC}$ foi refletido pela licencianda.

"Outra reflexão concebida pelas leituras é que muitas vezes o conhecimento é produzido a partir das necessidades da sociedade. O contexto de Haber era caracterizado pelo monopólio por parte da Inglaterra do salitre e do guano (produtos utilizados como fertilizantes) oriundos do Chile e Peru. A Prussia necessitava importar grandes quantidades desse produto. Sendo assim, uma alternativa à utilização dos mesmos necessitava ser criada. Além disso, como a demanda por estes 
produtos eram muito grande, estes viriam a se esgotar em pouco tempo. A Prússia então carecia que novos fertilizantes fossem produzidos. Estes fertilizantes eram constituidos de nitratos, que são nutrientes importantes para o solo, porém, pouco disponiveis na natureza. Dai o interesse em alternativas que viabilizassem a produção da amônia em larga escala. Isto certamente nos faz lembrar a impossibilidade de desvincular a ciência da sociedade. É importante lembrar que Haber não direcionou seus estudos a sintese da amônia, produção de gases, producão de catalisadores, etc. meramente por afinidade por estes conteúdos. Ao contrário, havia todo um contexto social, político e econômico que fizeram com que Haber escolbesse estes temas como objeto de estudo. Isto fica evidente na fala de Haber em seu discurso de premiação com o Nobel: 'A necessidade de viabilizar novas fontes de nitrogênio se tornou claramente visivel na virada do século. Desde a metade do século nós vínhamos aproveitando o suprimento de nitrogênio do salitre que a natureza tinha depositado nos desertos montanhosos do Chile. Comparando o rápido crescimento da demanda com a extensão calculada desses depósitos, ficou claro que em meados do século atual uma emergência seriíssima seria inevitável, a menos que a química encontrasse uma saída”.' [US 8.3]

Nessa US a licencianda utilizou argumentos baseados no contexto social da Prússia para justificar a necessidade de produzir amônia, afirmando que pelos fatores citados não é possível "desvincular a ciência da sociedade". A licencianda refletiu nessa US como o contexto "social, político e econômico" foram fatores determinantes para que Haber se dedicasse aos estudos da síntese da amônia, como afirmado por ele mesmo no trecho do discurso apresentado pela licencianda.

A categoria "o conhecimento científico é produzido de forma colaborativa" foi ressaltada pela licencianda nas US 7.4 e US 8.4. Nessas US a licencianda refletiu sobre a colaboração financeira e de outros cientistas à pesquisa de Fritz Haber, justificando assim esse aspecto de NdC, como mostra a US 8.4 a seguir.

"A bistória de Fritz. Haber também é um exemplo nítido de que cientistas não são pessoas sozinhas e solitárias. Haber contou com a ajuda de outros cientistas para que seus estudos pudessem progredir, como Carl Bosh, que contribuiu no sentido de viabilizar a produção de amônia em larga escala. Além disso, Haber contou com o apoio financeiro da empresa BASF para realizar sua pesquisa. Isto nos leva a pensar que o trabalho de Haber não se limitava apenas em utilizar seus conhecimentos técnico-cientificos, mas antes, ele precisava convencer outras pessoas de que seu trabalho era promissor e fazer com que pudessem apoiá-lo”. [US 8.4]

Nessa US a licencianda refletiu sobre a importância da colaboração financeira da empresa BASF e do cientista Carl Bosh, que viabilizou a realização da pesquisa de Haber, reconhecendo assim, que a construção do conhecimento não acontece sem colaborações.

A categoria “a ciência não é linear” foi identificada nas US 7.5 e 8.1. Nessas US a licencianda refletiu sobre os obstáculos enfrentados por Haber na produção da amônia, justificando o caráter não linear da ciência, como mostra a US 8.1.

"Ao ler sobre o estudo realizado por Haber ao longo de 10 anos, foi possivel constatar o caráter não linear e descontínuo da ciência. É comum a concepção de que o trabalho de um cientista se resume a levantar uma questão, elaborar hipóteses e realizar experimentos que surpreendentemente irão fundamentar estas hipóteses, fažndo com que estas se tornem "verdades". Ao averiguar 
o trabalho que Haber e cientistas anteriores a ele tiveram para tentar sintetizar a amônia, é possivel perceber que a ciência está imbuida de tentativas frustradas, resultados que nem sempre correspondem às expectativas, e vários outros obstáculos. Neste sentido, as tentativas sem sucesso de sintetizar a amônia foram tantas, que gerou a concepção de que este processo seria impossivel de ser realizado, acarretando em um preconceito geral entre as pessoas do círculo químico quanto ao estudo dessa sintese. Ao analisar todo o trabalho feito por Haber até que este chegasse a um resultado satisfatório, fica evidente que foi necessário um grande esforço para a solução dos inúmeros problemas com os quais teve de se deparar. Uma reação que envolva a mistura de $\mathrm{H}_{2}$ $e \mathrm{~N}_{2}$ para formar a amônia aparenta ser um processo simples. Entretanto, Haber teve de lidar com todo um espectro de obstáculos para tornar este projeto exequivel, que iam desde a procura da pressão, temperaturas e catalisadores adequados para que a reação acontecesse, até a projeção de equipamentos que fossem capazes de executar essa reação". [US 8.1]

Nessa US, a licencianda refletiu sobre a inexistência de um método científico que leva o cientista obter uma "verdade", sobre a dificuldade dos cientistas em produzir amônia em larga escala, o que fez com que muitos deles desistissem de realizar essa pesquisa. Desse modo, a licenciada justificou o que afirmou no início da US, "o caráter não linear e descontínuo da ciência".

A categoria "a ciência é um empreendimento humano" foi constatada nas US 7.2 e 8.2. Nessas US a licencianda refletiu sobre como os sentimentos, desejos e sonhos interferem na maneira como o conhecimento científico é produzido, e como a história de Haber ilustra bem esse aspecto de $\mathrm{NdC}$.

"Vale lembrar que todas estas falhas que acontecem no processo de producão do conbecimento são inteiramente justificáveis, uma vez que a ciência éproduzida por seres humanos, que são passíveis de erros. Considerando ainda o fato de que a ciência é uma produção humana, é importante ressaltar que sentimentos, desejos e necessidades são aspectos que influenciam fortemente na produção de conbecimento. No caso de Haber, é bastante claro que seu sentimento nacionalista, bem como o seu desejo de ver sua nação desenvolvida e independente, são fatores que o impulsionaram a dedicar seus estudos à sintese da amônia. Seu desejo de ver seu país vitorioso na guerra fez. também com que Haber se dedicasse a estudar a producão de gases, que seriam utilizados como armas quimicas pelo exército alemão. Talvez estes fatores sejam os que mais contribuam para nos fazer enxergar o caráter humano da ciência. Esta última muitas vezes parece ser um componente completamente alheio e dissociado das nossas características humanas. Contudo, a ciência é, mesmo que indiretamente, fortemente influenciada por estas características”. [US 8.2]

$\mathrm{Na}$ US 8.2, a licencianda ressaltou que a ciência é um empreendimento humano, o que justifica "as falhas que acontecem no processo de produção do conhecimento científico". Ela refletiu também sobre como as questões pessoais influenciam as escolhas do cientista e mostram "o caráter humano da ciência".

A categoria "a ciência é amoral" foi identificada apenas uma vez, na US 6.2, na qual a licencianda escreveu:

"Em relação ao prêmio Nobel recebido por Haber, muito se discutiu naquela época se este realmente merecia tal premiação, uma vez que foi considerado um criminoso de guerra devido aos seus estudos sobre armas quimicas. Contudo, é importante ressaltar que Haber estava sendo 
contemplado com um prêmio Nobel de química e não da Pa₹. Neste sentido, os critérios para a concessão do prêmio Nobel de química é que o cientista tenha contribuido para o desenvolvimento da ciência e da bumanidade. Haber recebeu o prêmio Nobel pela sintese da amônia e quanto a isto, não há dúvidas de que este conhecimento foi importante não só para a ciência, mas como também para a sociedade alemã, uma vez que impediu que uma crise na produção de alimentos ocorresse. Se o conbecimento produzido por certa pessoa for utilizado para fins não éticos perante a sociedade, outros cientistas deveriam ser julgados por esta lógica” [US 6.2]

Nessa US, a licencianda expressou em sua reflexão a ideia de que a ciência não pode ser rotulada como boa ou má, mas que os usos do conhecimento científico podem trazer boas ou más consequências para a sociedade. Percebese aqui, a compreensão de que o conhecimento científico é livre de julgamentos morais, diferentemente das consequências da atitude do ser humano. Essa reflexão nos parece problemática, pois remete a uma visão socialmente neutra da ciência, uma vez que a licencianda pareceu desconsiderar as responsabilidades éticas dos cientistas, enquanto membros da sociedade.

Vale ressaltar, no entanto, que essa compreensão foi expressa apenas nesse momento específico. Em várias outras ocasiões, como aquelas em que refletiu que a ciência é contextualizada (US 6.1; 6.3; 7.1; 7.3 e 8.3), ela sinalizou elementos que influenciam o fazer científico. Isso nos leva a supor que a expressão daquela reflexão pode ter sido influenciada pelo fato da licencianda compor o grupo a favor da concessão do prêmio Nobel de química a Fritz Haber durante o júri simulado. Por esse motivo, ela pode ter se utilizado de terminologias semelhantes àquelas empregadas no júri, sem problematizá-las.

\section{CONSIDERACִ̃̃ES FINAIS}

A presente pesquisa teve como objetivo analisar as compreensões sobre $\mathrm{NdC}$ de uma licencianda em química a partir de suas reflexões sobre um estudo de caso histórico expressas em seu portfólio. A análise evidenciou a compreensão de $\mathrm{NdC}$ da licencianda de forma contextualizada, isto porque, os aspectos de $\mathrm{NdC}$ ressaltados por ela emergiram de suas reflexões sobre o caso histórico, sendo estes apresentados com justificativas e/ou exemplos.

A partir das categorias geradas pela análise textual discursiva há indícios de que a licencianda percebeu que a ciência influencia e pode ser influenciada por diferentes contextos e fatores, evidenciando uma visão não neutra do empreendimento científico. Isso porque ela refletiu sobre como o contexto e fatores como os sociais e econômicos influenciaram o desenvolvimento da pesquisa de Fritz Haber. Nossa análise demonstrou que ela percebeu as complexidades das colaborações entre cientistas, e os obstáculos que, por vezes, podem fazer alguns deles desistirem de continuar suas pesquisas ou buscar outros caminhos, ou seja, ela foi capaz de visualizar a ciência como não linear. Isso foi evidente em suas reflexões sobre as colaborações recebidas por Haber e sobre as dificuldades enfrentadas por ele e outros cientistas na condução de pesquisas para a síntese da amônia.

A licencianda mostrou também a compreensão de que a ciência é produzida por pessoas normais, que são "passíveis de erro", ao refletir que a ciência é um 
empreendimento humano e, por isso, produzida por pessoas que podem cometer erros. E ainda que, a ciência não pode ser rotulada como boa ou má, mas que os usos do conhecimento científico podem trazer boas ou más consequências para a sociedade. Isso esteve presente em suas reflexões sobre o uso do conhecimento para fins considerados não éticos.

Esses resultados sugerem potencialidades de se conjugar estudos de caso e portfólios na formação inicial de professores de ciências para propiciar momentos de reflexões sobre $\mathrm{NdC}$. Isto porque estudos de caso histórico constituem-se de descrições densas e profundas, que têm a possibilidade de retratar a ciência a partir da análise dos contextos internos e externos a ela e das práticas dos cientistas imbricadas na produção de conhecimentos nestes contextos.

No caso desta pesquisa, o contexto analisado - a síntese da amônia em escala industrial a partir da problematização da premiação do cientista Fritz Haber - foi propício para que a licencianda ampliasse sua compreensão sobre ciência. Isto foi possibilitado também pelo uso do portfólio que, pelo fato de ser um instrumento aberto, não padronizado e elaborado ao longo do processo de ensino, favoreceu que a licencianda articulasse, justificasse e elaborasse de forma livre suas ideias sobre o que caracteriza a ciência. De acordo com Hernández (1998), a constante reflexão realizada pelo sujeito é um dos aspectos que caracteriza o portfólio como um instrumento de avaliação de suas compreensões.

Além do portfólio possibilitar a reflexão constante e contextualizada sobre $\mathrm{NdC}$ pela licencianda, identificamos momentos em que ele possibilitou também a sua autoavaliação e metacognição. Isso pode ser observado nos momentos em que a licencianda avaliou seus conhecimentos e refletiu sobre o que pensava sobre ciência. Por exemplo, quando reconheceu que "possuía uma visão de ciência muito idealizada e minimalista em relação a como ela é de verdade", tomando assim, consciência do seu conhecimento.

Diante desses apontamentos sobre as contribuições do portfólio sustentadas pelos resultados deste estudo, somos levadas a conjecturar que, se em lugar deste instrumento de avaliação, tivéssemos utilizado outro, como um questionário, por exemplo, este poderia não permitir que a licencianda selecionasse evidências de aprendizagem e refletisse sobre elas como o fez na produção do portfólio. Isso porque, enquanto em um questionário as questões podem acabar guiando o pensamento do sujeito, e de certa forma limitar o que ele tem a dizer, no portfólio a escrita é livre e o sujeito deve refletir sobre aquilo que ele julga ser mais importante.

Em outras palavras, ainda que as orientações quanto à forma de elaborar um portfólio sejam necessárias, de modo a garantir a compreensão do objetivo de sua elaboração, é o sujeito que determina o que deve compor o portfólio. Isso enriquece as informações contidas no mesmo, pela tomada de decisão, pela seleção de evidências do aprendizado, pelos julgamentos de desempenho e pela reflexão que ficam a cargo do sujeito neste instrumento.

Assim, acreditamos no potencial do portfólio como instrumento de avaliação das compreensões sobre $\mathrm{NdC}$ de professores, em especial, nos casos em que a investigação é realizada em processos de aprendizagem e reflexão sobre o tema, como na análise de estudos de caso.

Apesar dos resultados positivos que obtivemos com o uso deste instrumento, ainda são poucas as pesquisas que o utilizam na formação de 
professores em geral e de ciências em particular. Neste sentido, espera-se que os resultados deste trabalho inspirem pesquisas futuras, a fim de atender às demandas sobre avaliação dos conhecimentos sobre ciência de professores em formação.

\section{CONTRIBUIC̣ÃO DOS AUTORES:}

O autor 1 analisou os dados e escreveu o artigo. Os autores 2 e 3 analisaram os dados e revisaram o artigo. Todos os autores leram e aprovaram o manuscrito final.

\section{AGRADECIMENTOS}

O presente trabalho foi realizado com apoio da Coordenação de Aperfeiçoamento de Pessoal de Nível Superior - Brasil (CAPES) - Código de Financiamento 001 e Conselho Nacional de Desenvolvimento Científico e Tecnológico (CNPq).

\section{REFERÊNCIAS}

ACEVEDO-DÍAZ, J. A. Enfoques explícitos versus implícitos en la enseñanza de la naturaleza de la ciencia. Revista Eureka sobre Enseñanza y Divulgación de las Ciencias, v. 6, n. 3, p. 355-386, 2009.

ACEVEDO-DÍAZ, J. A.; GARCÍA-CARMONA, A. «Algo antiguo, algo nuevo, algo prestado». Tendencias sobre la naturaleza de la ciencia en la educación científica. Revista Eureka sobre Enseñanza y Divulgación de las Ciencias, v. 13, n. 1, p. 3-19, 2016.

ACEVEDO-DÍAZ, J. A.; VÁZQUEZ-ALONSO, A., MANASSERO-MAS, M. M.; ACEVEDOROMERO, P. Consensos sobre la naturaleza de la ciencia: fundamentos de una investigación empírica. Revista Eureka sobre Enseñanza y Divulgación de las ciencias, v. 4, n. 1, p. 42-66, 2007.

ALLCHIN, D. Evaluating Knowledge of the Nature of (Whole) Science. Science Education, v. 95, n. 3, p. 918-945, 2011.

ALLCHIN, D. Teaching the Nature of Science: Perspectives \& Resources. Minneapolis: Itascal, 2013.

ALLCHIN, D.; ANDERSEN, H. M.; NIELSEN, K. Complementary approaches to teaching nature of science: integrating student inquiry, historical cases, and contemporary cases in classroom practice. Science Education, v. 98, n. 3, p. 461-486, 2014.

ALVARENGA, G. M.; ARAUJO, Z. R. Portfólio: conceitos básicos e indicações para utilização. Estudos em avaliação educacional, v. 17, n. 33, p. 137-148, 2006.

AZEVEDO, N. H.; SCARPA, D. L. Revisão sistemática de trabalhos sobre concepções de natureza da ciência no ensino de ciências. Revista Brasileira de Pesquisa em Educação em Ciências, v. 17, n.2, p. 579-619, 2017a.

AZEVEDO, N. H.; SCARPA, D. L. Decisões envolvidas na elaboração e validação de um questionário contextualizado sobre concepções de natureza da ciência. Investigações em Ensino de Ciências, v. 22 , n. 2 , p. $57-82,2017$ b.

BARTHOLOMEW, H.; OSBORNE, J.; RATCLIFFE, M. Teaching students "ideas-about-science": Five dimensions of effective practice. Science Education, v. 88, n. 5, p. 655-682, 2004. 
COLLINS, A. Portfolios for science education: Issues in purpose, structure, and authenticity. Science Education, v. 76, n. 4, p. 451-463, 1992.

ELBY, A.; HAMMER, D. On the substance of a sophisticated epistemology. Science Education, v. 85 , n. 5 , p. 554-567, 2001.

GUERRA-RAMOS, M. T. Teachers' ideas about the nature of science: A critical analysis of research approaches and their contribution to pedagogical practice. Science \& Education, v. 21, n. 5, p. 631-655, 2012.

HERNÁNDEZ, F. Transgressão e mudança na educação: os projetos de trabalho. Porto Alegre: Artmed Editora, 1998.

HODSON, D. Nature of science in the science curriculum: Origin, development, implications and shifting emphases. In: MATTHEWS, M. (ed.). International handbook of research in history, philosophy and science teaching. Dordretch: Springer, 2014, p. 911-970.

IREZ, S. Are we prepared?: An assessment of preservice science teacher educators' beliefs about nature of science. Science Education, v. 90, n. 6, p. 1113-1143, 2006.

IRZIK, G.; NOLA, R. A family resemblance approach to the nature of science for science education. Science \& Education, v. 20, n. 7-8, p. 59-607, 2011.

IRZIK, G.; NOLA, R. New Directions for Nature of Science Research In: MATTHEWS, M. (Ed.). International Handbook of Research in History, Philosophy and Science Teaching. Dordretch: Springer, 2014, p. 999-1021.

IZQUIERDO-AYMERICH, M.; ADÚRIZ-BRAVO, A. Epistemological Foundations of School Science. Science \& Education, v. 12, n. 1, p. 27-43, 2003.

JUSTI, R.; MENDONÇA, P. C. C. Discussion of the Controversy Concerning a Historical Event Among Pre-service Teachers. Science \& Education, v. 25, n. 7-8, p. 795-822, 2016.

KIMBALL, M. E. Understanding the nature of science: A comparison of scientists and science teachers. Journal of Research in Science Teaching, v. 5, n. 2, p. 110-120, 1968.

KISH, C. K. et al. Portfolios in the classroom: A vehicle for developing reflective thinking. The high School journal, v. 80, n. 4, p. 254-260, 1997.

LEDERMAN, N. G. Students' and teachers' conceptions of the nature of science: A review of the research. Journal of research in science teaching, v. 29, n. 4, p. 331-359, 1992.

LEDERMAN, N. G. Nature of science: past, present, and future. In: ABELL, S. K. e LEDERMAN, N. G. (Ed.). Handbook of research on science education. Mahwah: Lawrence Erlbaum Associates, p. 831-880, 2007.

LEDERMAN, N. G. ABD-EL-KHALICK, F.; BELL, R. L.; SCHWARTZ, R. S. Views of Nature of Science Questionnaire: Toward Valid and Meaningful Assessment of Learner's Conceptions of Nature of Science. Journal of Research in Science Teaching, v. 39, n. 6, p. 497-521, 2002.

LEDERMAN, N. G.; WADE, P. D.; BELL, R. L. Assessing the nature of science: what is the nature of our assessments? Science \& Education, v. 7, n. 6, p. 595-615, 1998.

LÜDKE, M.; ANDRÉ, M. E. D. A. Pesquisa em educação: abordagens qualitativas. Rio de Janeiro: Editora Anthares, 2015. 
MOURA, C.; CAMEL, T.; GUERRA, A. A Natureza da Ciência pelas lentes do currículo: normatividade curricular, contextualização e os sentidos de ensinar sobre ciências. Ensaio Pesquisa em Educação em Ciências (Belo Horizonte), v. 22, p. 1-27, 2020.

NOT'T, M.; WELLINGTON, J. Critical incidents in the science classroom and the nature of science? School Science Review, v.76, n. 276, p. 41-46, 1995.

NOT'T, M.; WELLINGTON, J. Probing teachers' views of the nature of science: How should we do it and where should we be looking? In: WELFORD, G., OSBORNE, J.; Scott, P. (Eds.), Research in science education in Europe: Current issues and themes. London: Falmer Press, p. 283, 1996.

MATTHEWS, M. R. In defende of modest goals when teaching about the Nature of Science Journal of Research in Science Teaching, v. 35, n. 2, p. 161-174, 1998.

MCCOMAS, W. F. Seeking historical examples to illustratte key aspects of the nature of science Science \& Education, v. 17, n. 2-3, p. 249-263, 2008.

MENDONÇA, P. C. C. De que Conhecimento sobre Natureza da Ciência Estamos Falando? Ciência \& Educação (Bauru), v. 26, 2020.

MORAES, R. Uma tempestade de luz: a compreensão possibilitada pela análise textual discursiva. Ciência \& Educação (Bauru), v. 9, n. 2, p. 191-211, 2003.

MORAES, R.; GALIAZZI, M. D. C. Análise textual discursiva: processo reconstrutivo de múltiplas faces. Ciência \& Educação (Bauru), v. 12, n. 1, p. 117-128, 2006.

NIELSEN, K. H. Scientific communication and the nature of science Science \& Education, v. 22, n. 9, p. 2067-2086, 2012.

OLIVEIRA, T. M. A.; MOZZER, N. B.; ANDRADE, G. M. d. P. C. Modelo de conhecimento profissional de professores em formação. Enseñanza de las Ciencias, v. extra, p. 2805-2010, 2017.

PAULSON, F. L.; PAULSON, P. R.; MEYER, C. A. What Makes a Portfolio a Portfolio? Educational leadership, v. 48, n. 5, p. 60-63, 1991.

PORTO, P. A. História e Filosofia da Ciência no Ensino de Química: em busca dos objetivos educacionais da atualidade. Ensino de Química em Foco. 2ª ed. Ijuí: Editora Unijuí, p. 141-156, 2019.

SANTOS, M.; MAIA, P.; JUSTI, R. (2020). Um Modelo de Ciências para Fundamentar a Introdução de Aspectos de Natureza da Ciência em Contextos de Ensino e para Analisar tais Contextos. Revista Brasileira De Pesquisa Em Educação Em Ciências, v. 20, p. 581- 616, 2020.

QVORTRUP, A.; KEIDING, T. B. Portfolio assessment: production and reduction of complexity. Assessment \& Evaluation in Higher Education, v. 40, n. 3, p. 407-419, 2015.

RIBEIRO, C. Metacognição: um apoio ao processo de aprendizagem. Psicologia: reflexão e crítica, v. 16, n. 1, p. 109-116, 2003.

RODRIGUES, M. F. C. C. Portfolio: estratégia formativa e de reflexão na formação inicial em educação de infância, 2009, 240f. Dissertação (Mestrado em Ciências da Educação) - Faculdade de Psicologia e Ciências da Educação, Universidade de Lisboa, Lisboa, Portugal, 2009.

SÁ-CHAVES, I. Portfólios Reflexivos: estratégia de formação e de supervisão. Aveiro: Universidade, 2000.

SILVA, E. M. A.; ARAÚJO, C. M. Reflexão em Paulo Freire: uma contribuição para a formação 
continuada de professores. V Colóquio Internacional Paulo Freire, Recife, 2005.

SMITH, M. U.; SCHARMANN, L. C. Defining versus describing the Nature of Science: A pragmatic analysis for Classroom Teachers and Science Educatiors. Science Education, v. 85, n. 4, p. 493-504, 1999.

VIEIRA, V. M. D. O. Portfólio: uma proposta de avaliação como reconstrução do processo de aprendizagem. Psicologia escolar e educacional, v. 6, n. 2, p. 149-153, 2002.

VILLAS BOAS, B. M. F. Portfólio, avaliação e trabalho pedagógico. Campinas: Papirus Editora, 2005.

WONG, S. L.; HODSON, D. More from the Horse's Mouth: What scientists say about science as a social practice. International Journal of Science Education, v. 32, n. 11, p. 1431-1463, 2010.

ZANELLATO, J. R. Portfólio como Instrumento de avaliação no ensino de graduação em artes visuais, 2008, 124f. Dissertação (Mestrado em Educação) - Centro de Ciências Sociais Aplicadas, Universidade Católica de Campinas, Campinas, São Paulo, 2008.

\section{NOTAS}

1 Existem outras abordagens consensuais na literatura da área, discutimos a de Lederman e seus colaboradores pela relevância da mesma na área de pesquisa. Para mais detalhes, sugerimos consultar Acevedo-Díaz e García-Carmona (2016).

2 Os casos contemporâneos podem ser compreendidos como casos da história da ciência que ainda são controversos e cujos temas ainda estão em discussão na comunidade científica. Eles envolvem conhecimentos os quais a ciência ainda não chegou a um consenso. Por exemplo, os benefícios de alimentos transgênicos para a alimentação e as causas e consequências do aquecimento global para o meio ambiente (ALLCHIN et al., 2014).

\section{Submetido em 15/09/2020 \\ Aprovado em 07/12/2020}

\section{Contato:}

Universidade Federal de Ouro Preto

Campus Universitário Morro do Cruzeiro, Bauxita, $\mathrm{s} / \mathrm{n}^{0}$

CEP 35.400-000 - Ouro Preto, MG - Brasil 